\title{
Experience of Vaginoplasty for Enhancement of Sexual Functioning in a Center in Turkey: A Before and After Study
}

Gokcen Erdogan ${ }^{1}$

1. Gynecology and Obstetrics, Near East University Medical Faculty, Nicosia, CYP

Corresponding author: Gokcen Erdogan, mdgokcenerdogan@yahoo.com

\section{Abstract}

\section{Objective}

The number of vaginal rejuvenation procedures for improvement of sexual function is dramatically increasing worldwide. The objective of this study was to present our experience with women who presented to our clinic with the complaint of sexual dysfunction or desire to enhance sexual function or orgasm.

\section{Methods}

Demographic and descriptive data of the patients were evaluated. In addition, sexual dysfunction of the patients who underwent vaginoplasty in our center were evaluated before and after vaginoplasty procedure using Golombok Rust Inventory of Sexual Satisfaction (GRISS) scale and the scores were compared before and after the procedure, which is used in the evaluation of sexual dysfunction by relationship counsellors and clinics.

\section{Results}

A total of 250 women who described a sensation of a wide or floppy vagina with lost or decreased ability to achieve orgasm were included in the study. The mean age of the patients was $38.51 \pm 9.126$ years. Of all women, $85.2 \%$ were college graduates. A history of normal vaginal delivery was found in $77.8 \%$ of the participants. The mean GRISS scores of "Infrequency", "Non-communication", "Dissatisfaction", "Nonsensuality”, "Avoidance”, “Anorgasmia” and "overall GRISS" scores were statistically significantly decreased, while the mean vaginismus score was significantly increased $(\mathrm{p}<0.01)$.

\section{Conclusion}

Highly satisfying outcomes regarding patient satisfaction were obtained from vaginoplasty procedures that we have performed.

Review began 04/19/2021 Review ended 04/25/2021 Published 04/30/2021

\section{() Copyright 2021}

Erdogan. This is an open access article distributed under the terms of the Creative Commons Attribution License CC-BY 4.0., which permits unrestricted use, distribution, and reproduction in any medium, provided the original author and source are credited.
Categories: Obstetrics/Gynecology

Keywords: sexual dysfunction, sexual satisfaction, vaginoplasty, golombok rust inventory of sexual satisfaction

\section{Introduction}

Sexuality and sexual activity are important determinants of quality of life (QoL) and life satisfaction. Sexual satisfaction perceived individually by each person is a crucial component of sexual activity. Sexual health focuses not only on treatment, but also on achieving the highest level of well-being, QoL and sexual pleasure or satisfaction as possible. Female sexual functioning is influenced by previous vaginal delivery, ageing, genetic factors, relationships with the partner and other psychosocial factors. These factors may cause several disorders ranging from sexual dissatisfaction to actual deviation.

After vaginal trauma, most commonly vaginal delivery, women may encounter vaginal laxity due to stretching of local tissue and separation of the pelvic floor musculature. Postpartum vaginal laxity causes a gaping perineum, decreasing sensation of friction and sexual satisfaction [1]. There is abundant epidemiological evidence that vaginal delivery is the strongest factor of pelvic floor disorders [2]. Women with a history of vaginal delivery, and especially multiparous women may complain of alterations in sexual satisfaction, decreased friction during intercourse, changes in vaginal sensation and a general feeling of laxity [3-5]. In addition, women usually complain of the gaping of the vaginal vestibule that causes the appearance of vaginal mucosa [6]. This gaping leads to several functional concerns such as increased vaginal secretions due to mucosa exposure, alterations in achieving orgasm and vaginal air entrapment, which causes embarrassing sounds during intercourse [7].

Surgical vaginal tightening procedures are not new, although historically these procedures have been performed for obstetric postpartum repair rather than sexual and esthetic concerns [2]. Today, these 
procedures have increasingly gained popularity, although the line between enhancement of sexual functioning and medically indicated surgical procedures is a grey area and vaginal tightening procedures are performed for both purposes. The number of vaginal rejuvenation procedures for improvement of sexual function is dramatically increasing worldwide [8]. A few studies in the literature have shown that vaginal tightening procedures including vaginoplasty and perineoplasty are associated with enhanced sexual function with low rates of complications $[1,5]$. The reported minor complication rates vary between $3.8 \%$ and $19.7 \%$ [9].

The objective of this study was to retrospectively investigate the changes between pre- and postvaginoplasty sexual functioning parameters and to share our experience with women who presented to our clinic with the desire of enhancing sexual function or pleasure.

\section{Materials And Methods}

A total of 250 female patients who presented to our clinic and underwent vaginoplasty operation between January 2018 and April 2020 were retrospectively evaluated in the study. A detailed history was received from all patients at the time of admission and physical examinations were performed. The physical examination was performed both while a patient bears down and was in the lithotomy position, and the vaginal width and levator ani muscles were assessed [10]. After physical examination, patients were informed about vaginoplasty procedure, possible outcomes, complications and postoperative care, and gave written consent for the operation.

Patients using drugs affecting sexual function, those with symptomatic prolapsus (cystocele), rectocele or uterine prolapsus, patients with dyspareunia, primary anorgasmia or any psychological disorder (all patients were psychologically evaluated before the surgery), those with partner's sexual dysfunction, a history of pelvic surgery, those receiving radiotherapy for vaginal or cervical cancer, patients with chronic vaginal infections, those without intact pelvic floor support and who denied participation were excluded from the study.

Patients' demographic characteristics, educational status, childbearing status, number of children, history of vaginal delivery and cesarean section, and numbers of normal delivery and caesarean section were recorded and analyzed. In addition, sexual dysfunction of the patients was evaluated before and after vaginoplasty procedure using Golombok Rust Inventory of Sexual Satisfaction (GRISS) scale and GRISS scores were compared between before and after the procedure.

\section{Surgical technique}

Vaginoplasty procedure was performed following the procedure described by Moore et al. [11]. Accordingly, vaginoplasty procedure included the repair of the posterior vaginal canal and introitus and the modification of final diameter and caliber of the vagina to return its prenatal condition. Vaginoplasty procedure was performed under local anesthesia in some patients and under general anesthesia in the other patients who rejected local anesthesia. General anesthesia was performed under operating room conditions. Propofol, rocuronium bromide and fentanyl were used to induce anesthesia. The patients were intubated using laryngeal masks, airway or endotracheal tubes. Remifentanil was used for the maintenance of general anesthesia.

Since local anesthesia offers a reproducible, highly safe and relatively longer-duration anesthesia depending on the anesthetic agent used; local incisional anesthesia was chosen for vaginal esthetics procedures, and bupivacaine with $0.5 \%$ epinephrine was preferred as the anesthetic agent. During this anesthetic technique, both intravascular injection was avoided and attention was paid to not exceed toxic doses.

At the beginning of the procedure, inferior edges of the labia majora that will form the posterior fourchette of the vaginal opening were marked to create vaginal introitus during the closure. First, a typical trapezeshape incision that will also be used in the perineoplasty part of the procedure was made in the introitus. A small incision was then made in the posterior wall and the vaginal epithelium was laterally dissected from the underlying rectovaginal fascia out of the levators. The dissection was continued up to the apex so as to involve the entire posterior wall. The dissection of the vaginal epithelium was performed using Metzenbaum scissors and No. 20 scalpel. The vaginal caliber was then addressed by plication of the rectovaginal fascia with delayed absorbable sutures in the midline. Diameter of the vagina was continuously measured with fingers. A small amount of vaginal epithelium was then excised and the incision was closed with a running fashion. An appropriate amount of skin was excised from the perineum and introitus to provide an aesthetically satisfying appearance of vaginal opening and the procedure was completed with a multilayer repair. For the closure, figure-of-eight 2-0 Monocryl sutures approximated the levators. The superficial transverse perineal muscles and bulbocavernosus muscles were similarly approximated. The vaginal mucosa was closed using 2-0 running Vicryl, and the skin using 4-0 chromic suture.

\section{Golombok Rust Inventory of Sexual Satisfaction (GRISS)}

GRISS is a 28-items questionnaire used in the evaluation of sexual dysfunction in heterosexual couples. 
Each item is scored with a 5-point Likert scale (i.e. always to never). Raw points obtained from the scale are transformed to standard points between 0 and 9 .

GRISS is used by relationship counsellors and clinics in order to detect and follow-up sexual problems. This questionnaire has also been used in clinical trials in which new treatment approaches were applied. GRISS has two versions as female and male.

GRISS involves seven subscales with four questions in each. These subscales include anorgasmia, vaginismus, non-communication, infrequency, avoidance, non-sensuality and dissatisfaction. Participants were asked to fill the questionnaire form before vaginoplasty procedure and during control visit six months after the procedure. Filling of each form lasted for about 15 minutes. The questionnaire was developed by Rust and Golombok [12] and adopted to Turkish by Tugrul et al. [13], and evidence was obtained for reliability and validity of the questionnaire. In Turkish adaptation of GRISS, Cronbach alpha coefficient was found as 0.91 for overall score [13].

\section{Ethics considerations}

Before the beginning, the study protocol was approved by the local ethics committee of our hospital (Date:03/05/2020, No:003). The patients were informed about the objectives of the study and gave written consent. The study was conducted in accordance with the ethical principles of the Declaration of Helsinki.

\section{Statistical analysis}

Data obtained in this study were statistically analyzed using IBM SPSS version 23 statistical package software (SPSS, Statistical Package for Social Sciences, IBM Inc, Chicago, IL, USA). When evaluating study data, categorical variables are expressed as number and percentage, and numerical variables with mean \pm standard deviation among the descriptive statistics. Coefficient of skewness and kurtosis were examined for normality assumption of the numerical variables and the coefficients were found to be within the range of \pm 1.5. Therefore, parametric statistical methods were utilized in the analysis. Differences between two numerical variables (e.g. scale points before and after the procedure) were analyzed using a dependent sample t-test. $\mathrm{p}<0.05$ values were considered statistically significant.

Cronbach alpha coefficient of GRISS was calculated as 0.704 for pre-vaginoplasty and 0.836 for postvaginoplasty evaluations.

\section{Results}

A total of 250 patients who presented to our clinic with the desire of enhancing sexual functioning and underwent vaginoplasty between January 2018 and April 2020 were included in the study. The mean age of the patients was $38.51 \pm 9.126$ years. Of all women $41(16.4 \%)$ aged over 50 years. When educational status of the participants was examined; 213 (85.2\%) of the women were college graduates.

Only two (0.8\%) participants had no children. Childbearing women most commonly had two children (59.3\%). A history of normal vaginal delivery was found in 193 (77.8\%) women, while a history of cesarean section was found in 153 (61.2\%) women. Demographic features and descriptive characteristics of the participants are given in Table 1 . 


\section{Cureus}

\begin{tabular}{|c|c|c|}
\hline$(n=250)$ & Number & $\%$ \\
\hline \multicolumn{3}{|c|}{ Age (mean=38.51; SD=9.126) } \\
\hline $22-30$ years & 59 & 23.6 \\
\hline $31-39$ years & 80 & 32.0 \\
\hline 40-49 years & 70 & 28.0 \\
\hline 50 years and above & 41 & 16.4 \\
\hline \multicolumn{3}{|l|}{ Educational status } \\
\hline Middle school & 4 & 1.6 \\
\hline High school & 33 & 13.2 \\
\hline College & 213 & 85.2 \\
\hline \multicolumn{3}{|l|}{ Childbearing } \\
\hline Yes & 248 & 99.2 \\
\hline No & 2 & 0.8 \\
\hline \multicolumn{3}{|c|}{ Number of Children (n=248) } \\
\hline 1 & 46 & 18.5 \\
\hline 2 & 147 & 59.3 \\
\hline 3 & 48 & ${ }^{19.4}$ \\
\hline 4 & 7 & 2.8 \\
\hline \multicolumn{3}{|l|}{ Normal vaginal delivery } \\
\hline Yes & 193 & 77.8 \\
\hline No & 55 & 22.2 \\
\hline \multicolumn{3}{|c|}{ Number of normal vaginal deliveries $(n=193)$} \\
\hline 1 & 104 & 53.9 \\
\hline 2 & 63 & 32.6 \\
\hline 3 & 23 & 11.9 \\
\hline 4 & 3 & 1.6 \\
\hline \multicolumn{3}{|l|}{ Cesarean section } \\
\hline Yes & 153 & 61.2 \\
\hline No & 97 & 38.8 \\
\hline \multicolumn{3}{|c|}{ Number of cesarean sections (n=153) } \\
\hline 1 & 105 & 68.6 \\
\hline 2 & 48 & 31.4 \\
\hline
\end{tabular}

TABLE 1: Descriptive characteristics of the participants.

Sexual dysfunction and satisfaction of the participants were measured using GRISS scale. Accordingly, the mean infrequency score of the women was $6.18^{ \pm} 1.072$ before the procedure, while this score was decreased to $3.30 \pm 1.775$ after the procedure. The mean non-communication score was $7.64 \pm 1.072$ before vaginoplasty procedure and $5.93 \pm 1.598$ after vaginoplasty procedure. The mean dissatisfaction score was $6.58 \pm 0.903$

before the procedure, while this score was found as $4.24 \pm 1.319$ after the procedure. The mean non-sensuality score was $8.48 \pm 0.718$ before vaginoplasty procedure and $5.93 \pm 1.473$ after the procedure. The mean vaginismus score was $4.81 \pm 0.741$ before the procedure, while this score was calculated as $5.91 \pm 0.778$ after 


\section{Cureus}

the procedure. The mean anorgasmia score was $5.38 \pm 0.803$ before the intervention, while this score dropped to $3.99 \pm 0.946$ after the intervention.

The mean overall GRISS score was calculated as $7.32 \pm 0.724$ before vaginoplasty procedure and $4.52 \pm 1.457$ after vaginoplasty procedure. As a result of the dependent sample t-test; the mean scores of "Infrequency", "Non-communication", "Dissatisfaction", "Non-sensuality", "Avoidance", "Vaginismus", "Anorgasmia" and "GRISS" show statistically significant differences $(\mathrm{p}<0.05)$. The mean infrequency, non-communication, dissatisfaction, avoidance, non-sensuality, anorgasmi and overall GRISS scores were significantly decreased, while the mean vaginismus score was significantly increased (Table 2).

\begin{tabular}{|c|c|c|c|c|c|c|}
\hline & \multicolumn{2}{|c|}{ Before vaginoplasty } & \multicolumn{2}{|c|}{ After vaginoplasty } & \multirow{2}{*}{$t$} & \multirow{2}{*}{$p$} \\
\hline & Mean & SD & Mean & SD & & \\
\hline Infrequency & 6.18 & 1.072 & 3.30 & 1.775 & 26.984 & $0.000^{*}$ \\
\hline Non-communication & 7.64 & 0.964 & 5.93 & 1.595 & 14.551 & $0.000^{*}$ \\
\hline Dissatisfaction & 6.58 & 0.903 & 4.24 & 1.319 & 35.790 & $0.000^{*}$ \\
\hline Avoidance & 7.29 & 0.864 & 5.06 & 1.261 & 24.646 & $0.000^{*}$ \\
\hline Non-sensuality & 8.48 & 0.718 & 5.93 & 1.470 & 31.578 & $0.000^{*}$ \\
\hline Vaginismus & 4.81 & 0.741 & 5.91 & 0.778 & -18.567 & $0.000^{*}$ \\
\hline Anorgasmia & 5.38 & 0.803 & 3.99 & 0.946 & 27.606 & $0.000^{*}$ \\
\hline Total & 7.32 & 0.724 & 4.52 & 1.457 & 39.146 & $0.000^{*}+2>0$ \\
\hline
\end{tabular}

TABLE 2: Differences in Golombok Rust Inventory of Sexual Satisfaction (GRISS) and subscale scores before and after vaginoplasty.

${ }^{*} \mathrm{p}<0.05$ (statistically significant). $\mathrm{t}$ : dependent sample t-test.

Changes in the scores according to the subscales of GRISS scale are shown in Figure 1.

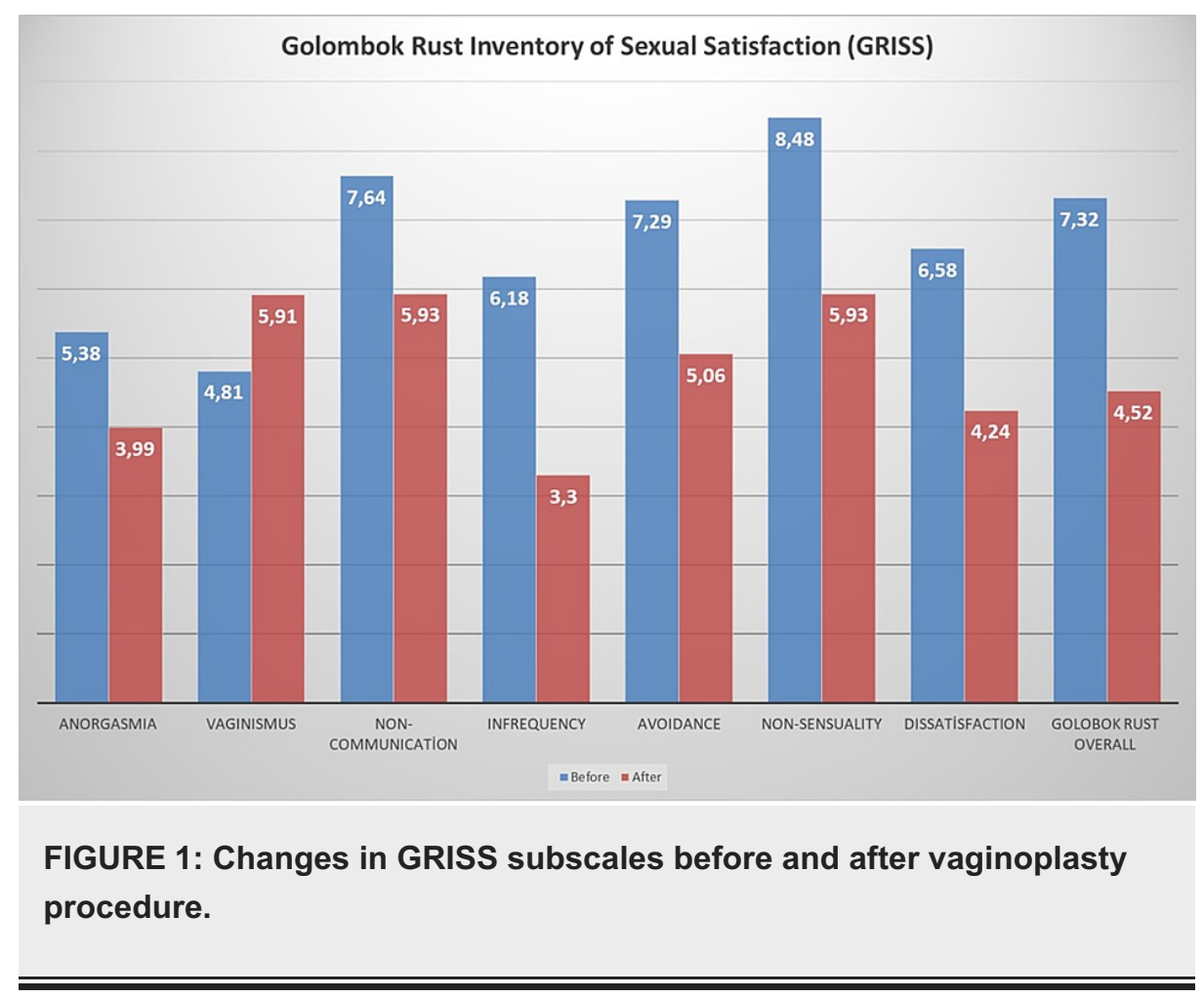




\section{Discussion}

Vaginoplasty and vaginal tightening procedures have become increasingly popular for cosmetic reasons, enhancement of sexual function, treatment of vaginal laxity and urinary incontinence, although scientific short-term and long-term evidence are lacking. Today, the most common indication for vaginoplasty performed to improve sexual function is sexual dysfunction due to vaginal laxity caused by normal vaginal delivery and natural ageing process. According to a survey conducted by the International Urogynecological Association in 2012, $84 \%$ of physicians believe that vaginal laxity is underreported and $95 \%$ think that laxity affects sexual function [14]. In addition, $40 \%$ of women have psychological distress resulted from sexual dysfunction, although only $14 \%$ of women counsel to a physician about sex during their lifetime [15]. As knowledge of patients on treatment options for vaginal laxity increases, demand for vaginoplasty will continue to grow. Today taboos on the communication about female dysfunction have broken owing to public awareness programs, physician education and media. Information about these conditions and their treatment are more readily available, increasing the demand for these procedures. In a study from India, demand for esthetic vaginal procedure has risen to $28.92 \%$ in 2015 from $3.9 \%$ in 2012 [16]. In a review of vaginal tightening procedures performed between 2014 and 2019 in Canada, Austin et al. reported that posterior vaginoplasty resulted in a high patient satisfaction without complications [17]. In our study, satisfying results were obtained in terms of patient satisfaction for enhancement of sexual functioning in patients who underwent vaginoplasty due to sexual dysfunction. The mean overall GRISS score was $7.32 \pm 0.724$ at the beginning of the study, while this score was decreased to $4.52 \pm 1.457$ after vaginoplasty procedure.

Information on vaginal rejuvenation procedures mostly comes from the Internet and scientific literature on this issue is very limited. The number of studies in the literature evaluating vaginoplasty performed for enhancement of sexual function is limited and these studies usually include specific patient groups and case reports $[3,18,19]$. In addition, numerous tools are used in order to measure satisfaction of patients undergoing vaginoplasty. This makes an exact comparison between our results and those reported in the literature difficult.

In a study by Austin et al., investigating patients who underwent vaginoplasty procedure, the mean age of the patient was found as 41 years [17]. In the present study, the mean age of the patients was found as $38.51 \pm 9.126$ years. The mean age of our patients was consistent with the literature.

In the study by Austin et al., majority of the patients (86.7\%) undergoing vaginoplasty were multiparous, while the remaining $13.3 \%$ patients were primiparous [17]. In our study, $80.8 \%$ of the participants were multiparous, while the remaining $19.2 \%$ patients were primiparous. These results are similar to the previously reported rates.

In a study by Crouch et al. in which outcomes of vaginoplasty procedures performed in women with congenital adrenal hyperplasia with GRISS, women who underwent vaginoplasty continued to complain of clitoris sensitivity, vaginal penetration difficulties and frequency of intercourse [20]. In our study, frequency of intercourse was increased by $87.27 \%$ after the procedure compared to before the procedure according to the GRISS scale.

In a multicenter cross-sectional study, 47 women underwent vaginoplasty/perineoplasty procedures and the outcomes showed a high satisfaction rate both for women and their partners in terms of the enhancement of sexual function [3]. In our study, the mean "dissatisfaction" subscale score was $6.58 \pm 0.903$ before vaginoplasty procedure, while this score dropped to $4.24 \pm 1.319$ after the procedure. In other words, sexual satisfaction was increased by $55.99 \%$ after the procedure.

When other findings of our study were examined; communication was increased by $28.84 \%$, sensuality by $43.00 \%$, achieving orgasm by $34.85 \%$ after the procedure compared to before the procedure, while avoidance was decreased by $44.07 \%$ and vaginismus by $22.87 \%$. These results indicated that our vaginoplasty applications were successful and provided satisfying outcomes for the patients. As mentioned before, because publications in the literature on this issue were lacking, our results could not be exactly compared with the results of other studies.

To our very knowledge, this study is the first in the literature to evaluate satisfaction of the patients undergoing vaginoplasty for enhancement of sexual functioning using GRISS scale. The results of our study will be guiding for further multicenter and comprehensive studies to be performed in future.

\section{Study limitations}

The main limitation of our study was lack of an exact comparison of the results with previous studies in the literature. In addition, the results could be compared with a control group. However, the number of our patients was relatively high for such a study. Finally, as a strength aspect this study is the first in the literature on this issue. 


\section{Conclusions}

Today, demand for vaginoplasty procedures is increasing due to medical problems as well as cosmetic reasons and desire to enhance sexual function. Highly satisfying outcomes regarding patient satisfaction were obtained from vaginoplasty procedures performed in our center. However, the number of studies on this issue are very limited. Further studies with large series are needed in order to better evaluate outcomes of these relatively new procedures and to shed light on future projections.

\section{Additional Information \\ Disclosures}

Human subjects: Consent was obtained or waived by all participants in this study. Near East University Ethics Committee issued approval Date:03/05/2020, No:003. Animal subjects: All authors have confirmed that this study did not involve animal subjects or tissue. Conflicts of interest: In compliance with the ICMJE uniform disclosure form, all authors declare the following: Payment/services info: All authors have declared that no financial support was received from any organization for the submitted work. Financial relationships: All authors have declared that they have no financial relationships at present or within the previous three years with any organizations that might have an interest in the submitted work. Other relationships: All authors have declared that there are no other relationships or activities that could appear to have influenced the submitted work.

\section{References}

1. Jamali S, Abedi P, Rasekh A, Mohammadjafari R: The long term effect of elective colpoperineoplasty on sexual function in the reproductive aged women in Iran. Int Sch Res Notices. 2014, 2014:912786. $10.1155 / 2014 / 912786$

2. Mant J, Painter R, Vessey M: Epidemiology of genital prolapse: observations from the Oxford Family Planning Association Study. Br J Obstet Gynaecol. 1997, 104:579-85. 10.1111/j.1471-0528.1997.tb11536.x

3. Goodman MP, Placik OJ, Benson RH 3rd, et al.: A large multicenter outcome study of female genital plastic surgery. J Sex Med. 2010, 7:1565-77. 10.1111/j.1743-6109.2009.01573.x

4. Ulubay M, Keskin U, Fidan U, et al.: Safety, efficiency, and outcomes of perineoplasty: treatment of the sensation of a wide vagina. Biomed Res Int. 2016, 2016:2495105. 10.1155/2016/2495105

5. Dobbeleir JM, Landuyt KV, Monstrey SJ: Aesthetic surgery of the female genitalia. Semin Plast Surg. 2011, 25:130-41. 10.1055/s-0031-1281482

6. Kanter G, Jeppson PC, McGuire BL, Rogers RG: Perineorrhaphy: commonly performed yet poorly understood. A survey of surgeons. Int Urogynecol J. 2015, 26:1797-801. 10.1007/s00192-015-2762-1

7. Ostrzenski A: Modified posterior perineoplasty in women. J Reprod Med. 2015, 60:109-16.

8. Goodman MP: Female genital cosmetic and plastic surgery: a review. J Sex Med. 2011, 8:1813-25. 10.1111/j.1743-6109.2011.02254.x

9. Goodman MP: Female cosmetic genital surgery. Obstet Gynecol. 2009, 113:154-9. 10.1097/AOG.0b013e318190c0ea

10. Pelosi MA: III, Pelosi MA, II. Perineoplasty and vaginoplasty. In: Hamori CA, Banwell PE, Alinsod R, eds. Female Cosmetic Genital Surgery: Concepts, Classification, and Techniques. New York, NY: Thieme Medical Publishers. 2017, 162-180.

11. Moore RD, Miklos JR, Chinthakanan O: Female Genital Plastic and Cosmetic Surgery. Female Genital Plastic and Cosmetic Surgery, First Edition. Surgical procedures II: perineoplasty, vaginoplasty, colpoperineoplasty (“vaginal rejuvenation”). Goodman MP (ed): John Wiley \& Sons, Ltd, New York; 2016. 88-101.

12. Rust J, Golombok S: The GRISS: a psychometric instrument for the assessment of sexual dysfunction . Arch Sex Behav. 1986, 15:157-65. 10.1007/BF01542223

13. Tuğrul C, Öztan N, Kabakçı E: Golombok-Rust Cinsel Doyum Ölçeği'nin Standardizasyon Çalışması. Turk Psikiyatri Derg. 1993, 4:83-8.

14. Pauls RN, Fellner AN, Davila GW: Vaginal laxity: a poorly understood quality of life problem; a survey of physician members of the International Urogynecological Association (IUGA). Int Urogynecol J. 2012, 23:1435-48. 10.1007/s00192-012-1757-4

15. ACOG Practice Bulletin No. 119: Female sexual dysfunction. Obstet Gynecol. 2011, 117:996-1007. 10.1097/AOG.0b013e31821921ce

16. Desai SA, Dixit VV: Audit of Female Genital Aesthetic Surgery: Changing Trends in India . J Obstet Gynaecol India. 2018, 68:214-20. 10.1007/s13224-018-1115-7

17. Austin RE, Lista F, Vastis PG, Ahmad J: Posterior vaginoplasty with perineoplasty: a Canadian experience with vaginal tightening surgery. Aesthet Surg J Open Forum. 2019, 1:ojz030. 10.1093/asjof/ojz030

18. Al-Badr A, Alkhamis WH: Laser vaginal tightening complications: report of three cases . Lasers Surg Med. 2019, 51:757-9. 10.1002/1sm.23110

19. Almasri J, Zaiem F, Rodriguez-Gutierrez R, et al.: Genital reconstructive surgery in females with congenital adrenal hyperplasia: a systematic review and meta-analysis. J Clin Endocrinol Metab. 2018, 103:4089-96. 10.1210/jc.2018-01863

20. Crouch NS, Liao LM, Woodhouse CR, Conway GS, Creighton SM: Sexual function and genital sensitivity following feminizing genitoplasty for congenital adrenal hyperplasia. J Urol. 2008, 179:634-8. 10.1016/j.juro.2007.09.079 